9. Standiford HC, Chan S, Tripoli M, Weekes E, Forrest GN. Antimicrobial stewardship at a large tertiary-care academic medical center: cost analysis before, during, and after a 7-year program. Infect Control Hosp Epidemiol 2012;33:338-345.
10. Valerio M, Muñoz P, Rodríguez CG, et al. Antifungal stewardship in a tertiary-care institution: a bedside intervention. Clin Microbiol Infect 2015; 21:492.e1-e9.

\title{
To err is human, to forget is device-related: A cautionary note for endoscopists
}

\author{
Mina SEM Said MD ${ }^{1}$, Ekta D. Tirthani $\mathrm{MD}^{1}$ and Emil P. Lesho DO ${ }^{2}$ \\ ${ }^{1}$ Department of Medicine, Rochester Regional Health, Rochester, New York and ${ }^{2}$ Infectious Diseases Unit, Rochester Regional Health, Rochester, New York
}

To the Editor-More than 5 million endoscopies are performed annually in the United States, and 1 in 1.8 million procedures is associated with a healthcare-related infection. ${ }^{1-3}$ However, the true rate of infection transmission during endoscopy is largely unrecognized because of the late onset of clinical symptoms after the procedure, underreporting, and other surveillance challenges. ${ }^{1-4}$

Risk factors for gastrointestinal (GI) infections after endoscopy include bacterial biofilm formation, inadequate decontamination, immunocompromised patients, presence of infective foci in the operating field, and equipment malfunction. Procedural endoscopies, such as variceal ligation, are associated with significantly higher infection transmission than diagnostic GI procedures. ${ }^{5-8}$

The disinfection of endoscopes involves a complicated, multistep process, and any retained object in one of its narrow channels, such as a sheath, could increase the microbial burden and the chance of an endoscopy-related infection, as illustrated by the following example. ${ }^{1,9,10}$ During a routine colonoscopy, the operator noticed resistance while advancing a vascular clipping wire through the channel. A sheath of a balloon-tipped catheter (M00558470 Boston Scientific CRE Wire-guided Esophageal/pyloric balloon dilation) was then extruded into the colonic lumen. The sheath and endoscope were withdrawn, and the procedure was completed with a different endoscope.

A standardized protocol for exposure investigation after a breach of disinfection procedure was followed. ${ }^{3}$ The last time that type of balloon-tipped catheter was used occurred 20 days prior, resulting in 20 patients having potentially been exposed. However, a tracking system linking the serial number of any endoscope in the clinic to every patient it is/was used on had been implemented 1 year previously. This procedure revealed that the involved endoscope was used on only 2 subsequent patients. Review of patient records who had endoscopies in that 20-day period reconfirmed the number of patients potentially exposed $(n=2)$.

Interrogation of the endoscope with various inserts revealed that the presence of a retained sheath would allow passage of all types of guide wires, (snips, snares, etc), including the cleaning

Author for correspondence: Emil Lesho, E-mail: carolinelesho@yahoo.com PREVIOUS PRESENTATION: This study was presented at the Sixth Decennial International Conference on Healthcare-Associated Infections in March 26, 2020, in Atlanta, Georgia.

Cite this article: Said MSEM, Tirthani ED, and Lesho EP. (2022). To err is human, to forget is device-related: A cautionary note for endoscopists. Infection Control \& Hospital Epidemiology, 43: 807-808, https://doi.org/10.1017/ice.2021.101 brush. The only device whose passage would have been prevented by a retained sheath was a vascular clipping device. Such clippings were performed as recently as 2 days prior to the incident, further confirming number of potentially exposed patients. Notably, this explained why the sheath had not been extruded by the cleaning brushes during the preparatory steps of reprocessing.

Exposed patients were notified and offered free testing for bloodborne and enteric pathogens. The county and state health departments were notified, and a MAUDE (Manufacturer and User Device Experience) report was filed with the US Food and Drug Administration. A search of the MAUDE database and PubMed revealed 2 similar incidents in the MAUDE database describing the failure of removal of the sheaths, which led to it being lodged in the endoscope compromising the disinfection process in one (June 14,2019), and in the other, leading to detachment of the exit marker (February 18, 2017). No similar cases were found in PubMed.

The root cause analysis revealed that 4 factors contributed to this incident. First, the assisting technologist was newly trained and inexperienced. Second, the rapid turnover of patients, insufficient number of endoscopes, and different models of catheters stocked heightened risk of reprocessing breakdown. Third, there was no count and verification for the number of removable components (similar to an operating-room sponge count). Last, there were 2 important design flaws. The first flaw pertains to the sheath design, having a size that allows it to enter the channel. Additionally, this brand lacks a large warning flag that also precludes channel sheath entry (Fig. 1). The second flaw pertains to the cleaning brushes that are not large enough to extrude a lodged sheath because they pass through the lumen of the embedded sheath. This permits the sheath to remain, undetected, in the endoscope during the preparatory steps of reprocessing.

The Boston Scientific sheath covering the balloon is flared at each end. However, there is no tag on the sheath stating to remove it prior to use the balloon. In contrast, the sheath of the Cook Medical balloon has a tag indicating its removal prior to insertion of the balloon, and it is also large enough that the provider would not be able to advance the balloon unless the sheath were removed (Fig. 1). Additionally, because sheaths are not conventionally counted after the procedure, there is a risk of them being left unnoticed within the lumen of the endoscope channel.

The following measures would help prevent the recurrence of this process breakdown. First, manufacturers should consider modifying the design of balloon sheaths and cleaning brushes. Sheaths should 


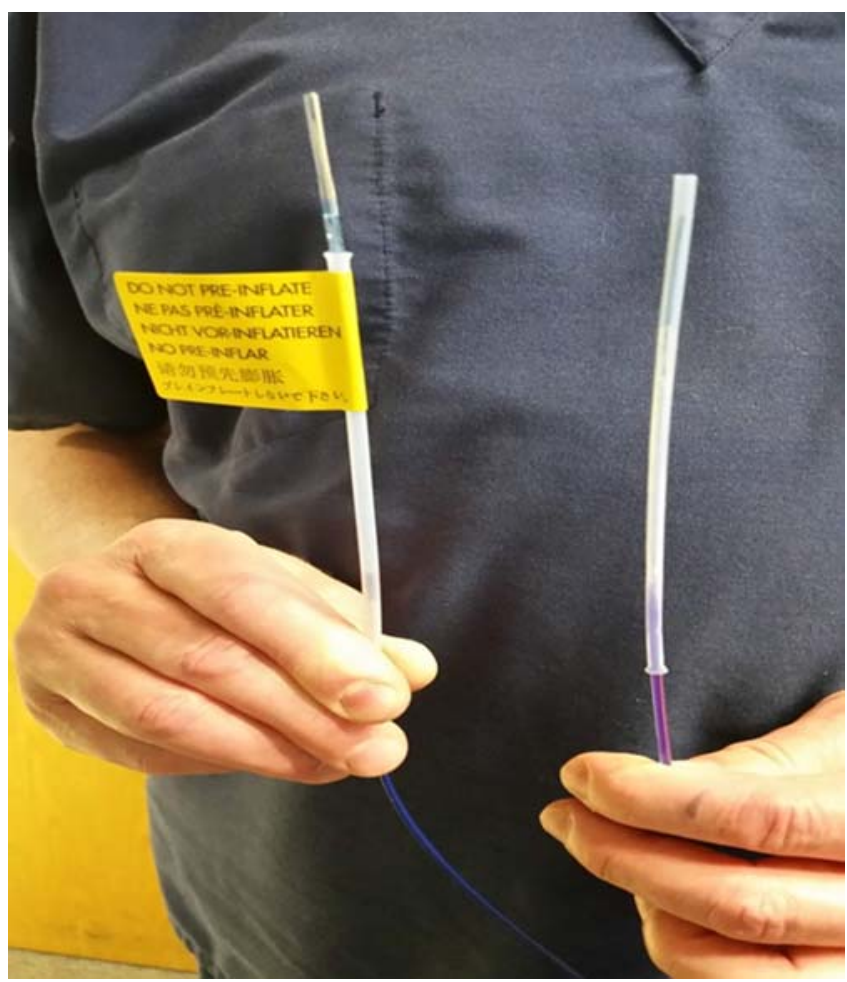

Fig. 1. Cook Medical balloon (left) and Boston Scientific balloon.

not fit into the endoscope channel, either because of their size or the attachment of a nonremovable flag. Cleaning brushes should not pass through the lumen of an embedded sheath, thus leading operators to believe the channel is unaltered and that the endoscope has been properly and completely cleaned and disinfected. Next, a sheath count, verified by a second person or 2-stage discarding by the same person, should be implemented. This step would occur during and at the end of the procedure. During the procedure, whenever a device is unpackaged and disposable components are removed, instead of immediately throwing out the packaging and components (ie, sheaths), they should be retained and then recounted and recorded during room turnover. Meticulous endoscope tracking and cleaning logs should be kept. Finally, new technologists should be made aware of these risks during their orientation. Since implementing the sheath counts and education, no similar incidents have occurred at our facility.

\section{Acknowledgments.}

Financial support. No financial support was provided relevant to this article.

Conflicts of interest. All authors report no conflicts of interest relevant to this article.

\section{References}

1. Griffiths H, Dwyer L. What every endoscopist should know about decontamination. Frontline Gastroenterol 2019;10:167-170.

2. Kovaleva J, Peters FT, van der Mei HC, Degener JE. Transmission of infection by flexible gastrointestinal endoscopy and bronchoscopy. Clin Microbiol Rev 2013;26:231-254.

3. Rutala WA, Weber DJ. How to assess risk of disease transmission to patients when there is a failure to follow recommended disinfection and sterilization guidelines. Infect Control Hosp Epidemiol 2007;28:146-155.

4. Nelson DB, Muscarella LF. Current issues in endoscope reprocessing and infection control during gastrointestinal endoscopy. World J Gastroenterol 2006;12:3953-3964.

5. Cowen AE. Infection and endoscopy: who infects whom? Scand J Gastroenterol Suppl 1992;192:91-96.

6. Greene WH, Moody M, Hartley R, et al. Esophagoscopy as a source of Pseudomonas aeruginosa sepsis in patients with acute leukemia: the need for sterilization of endoscopes. Gastroenterology 1974;67:912-919.

7. Kaw M, Przepiorka D, Sekas G. Infectious complications of endoscopic procedures in bone marrow transplant recipients. Dig Dis Sci 1993;38:71-74.

8. Nelson DB. Infectious disease complications of GI endoscopy: part I, endogenous infections. Gastrointest Endosc 2003;57:546-556.

9. Alvarado CJ, Reichelderfer M. APIC guideline for infection prevention and control in flexible endoscopy. Association for Professionals in Infection Control. Am J Infect Control 2000;28:138-155.

10. Beilenhoff U, Neumann CS, Rey JF, et al. ESGE-ESGENA guideline for quality assurance in reprocessing: microbiological surveillance testing in endoscopy. Endoscopy 2007;39:175-181.

\title{
Challenges for quality control of institutional bone banking in developing countries
}

\author{
Zeljko L. Stepanovic MD, $\mathrm{PhD}^{1,2}$ (1) and Branko M. Ristic MD, PhD ${ }^{1,2}$ \\ ${ }^{1}$ Clinic for Orthopedic and Trauma Surgery, University Clinical Center Kragujevac, Kragujevac, Serbia and ${ }^{2}$ Faculty of Medical Sciences, University in Kragujevac, \\ Kragujevac, Serbia
}

Author for correspondence: Zeljko L. Stepanovic, E-mail: zeljko.stepanovic@medf.kg.ac.rs PREVIOUS PRESENTATION. Some data in this study correspond with our previous reports on our institutional bone bank activities (Stepanovic ZL, Ristic BM. The effectiveness of bone banking in Central Serbia: audit of the first seven years. Cell Tissue Bank 2014;15:567-572 and Stepanović ŽLj, Ristić BM. Bacterial infections associated with allogenic bone transplantation. Vojnosanit Pregl 2015;72:427-430).

Cite this article: Stepanovic ZL and Ristic BM. (2022). Challenges for quality control of institutional bone banking in developing countries. Infection Control \& Hospital Epidemiology, 43: 808-810, https://doi.org/10.1017/ice.2021.102
To the Editor-To assess the contamination rate of retrieved bone allografts and the infection rate after bone allotransplantation, we performed the retrospective review of 2 audits to evaluate the quality of bone bank activities in the University hospital in Central Serbia using data from January 2007-December 2019.

Institutional bone banks are the widely accepted source of allogenic bone grafts. They are liable for their harvesting, testing, 